\title{
GESTÃO DO CONHECIMENTO E MÍDIAS SOCIAIS: MÉTODO DE BUSCA DE INFORMAÇÕES CONFIÁVEIS PARA INCENTIVAR PESQUISAS FUTURAS
}

\author{
KNOWLEDGE MANAGEMENT AND SOCIAL MEDIA: A SEARCH METHOD FOR RELIABLE INFORMATION TO \\ ENCOURAGE FUTURE RESEARCH
}

\section{LA GESTIÓN DEL CONOCIMIENTO Y LOS MEDIOS SOCIALES: MÉTODO DE BÚSQUEDA DE INFORMACIONES CONFIABLES PARA INCENTIVAR INVESTIGACIONES FUTURAS}

CELSO RICARDO SALAZAR VALENTIM

Doutor

Humantech Gestão do Conhecimento - Brasil

celso@humantech.com.br

LUCIANO VIGNOCHI

Doutor

Universidade do vale do Itajaí - Brasil

Ivignochi1@gmail.com

ÁLVARO GUILLERMO ROJAS LEZANA

Doutor

Universidade Federal de Santa Catarina - Brasil alvaro.lezana@ufsc.br

Submetido em: 21/04/2017

Aprovado em: 22/06/2017

Doi: alcance.v24n2.p285-305

\section{RESUMO}

Redes sociais corporativas compreendem interações imersas em um ambiente de ferramentas de mídias sociais. As empresas precisam entender a globalização impulsionada pela tecnologia da informação, sua influência na Gestão do Conhecimento e como usar Mídias Sociais para sobreviver e ganhar vantagem competitiva. 0 objetivo deste estudo é identificar como a Gestão do Conhecimento e as Mídias Sociais estão relacionadas na literatura científica para encorajar futuras pesquisas. $O$ método de mapeamento de conhecimento científico denominado Processo Construtivista de Desenvolvimento de Conhecimento (ProKnow- $C$ ) apoiou uma análise bibliométrica e sistêmica de literatura. O ProKnow- $C$ é uma opção para selecionar publicações científicas confiáveis segundo sua relevância. A análise dos dados exibe 42 artigos na base Science Direct entre janeiro de 2005 e fevereiro de 2017. Mostra as principais revistas, descreve conceitos e identifica metodologias utilizadas em artigos sobre Gestão do Conhecimento e Mídias Sociais. O ProKnow-C viabilizou buscar, organizar e analisar dados bibliográficos em conformidade com uma base de dados confiáveis. $\mathrm{Na}$ análise dos resultados identificaram-se lacunas e oportunidades de pesquisas futuras. Estudos em profundidade serão úteis para a perspectiva estratégica das corporações nas seguintes direções: influência nos ambientes interno e externo, identificação de ferramentas simples e úteis, razões da desistência de uso e influência de aspectos comportamentais e psicológicos sobre usuários.

Palavras-chave: Gestão do Conhecimento. Mídias Sociais. Pesquisas futuras. 


\begin{abstract}
Corporate social networks comprise interactions immersed in an environment of social media tools. Companies need to understand globalization driven by information technology, its influence on Knowledge Management, and how to use Social Media to survive and gain competitive advantage. The objective of this study is to identify how Knowledge Management and Social Media are related in the scientific literature, to encourage future research. The method of mapping scientific knowledge called the Constructivist Process of Knowledge Development (ProKnow-C) supported a bibliometric and systemic literature analysis. ProKnow-C is an option to select reliable scientific publications according to their relevance. The data analysis shows 42 articles in the Science Direct database from January 2005 to February 2017. It shows the main journals, describes the main concepts and identifies the methodologies used in publications about Knowledge Management and Social Media. The ProKnow-C enabled search, organize and analyze bibliographic data in accordance with a reliable database. In the analysis of the results, gaps were identified, as well as opportunities for further research. In-depth studies will be useful for the strategic perspective of corporations, in the following directions: influence in the internal and external environments, identification of simple and useful tools, reasons for the withdrawal of use, and the influence of behavioral and psychological aspects on users.
\end{abstract}

Keywords: Knowledge Management. Social Media. Future research.

\title{
RESUMEN
}

Las redes sociales corporativas comprenden interacciones inmersas en un ambiente de herramientas de medios sociales. Las empresas necesitan entender la globalización impulsada por la tecnología de la información, su influencia en la Gestión del Conocimiento y cómo usar los Medios Sociales para sobrevivir y ganar ventaja competitiva. El objetivo de este estudio es identificar cómo la Gestión del Conocimiento y los Medios Sociales son mencionados en la literatura científica para estimular futuras investigaciones. El método de mapeo de conocimiento científico denominado Proceso de Desarrollo del Conocimiento Constructivista (ProKnow-C) apoyó un análisis bibliométrico y sistémico de la literatura. El ProKNow-C es una alternativa para seleccionar publicaciones científicas confiables según su relevancia. El análisis de los datos exhibe 42 artículos en la base Science Direct entre enero de 2005 y febrero de 2017. Muestra las principales revistas, describe conceptos e identifica metodologías utilizadas en artículos sobre la Gestión del Conocimiento y los Medios Sociales. El ProKnow-C hizo posible buscar, organizar y analizar datos bibliográficos en conformidad con una base de datos confiables. En el análisis de los resultados se identificaron vacíos y oportunidades de investigaciones futuras. Será útil realizar estudios en profundidad para la perspectiva estratégica de las corporaciones en las siguientes direcciones: influencia en los ambientes interno y externo, identificación de herramientas sencillas y útiles, razones del desistimiento de uso e influencia de aspectos comportamentales y psicológicos sobre los usuarios.

Palabras clave: Gestión del Conocimiento. Medios Sociales. Investigaciones futuras.

\section{INTRODUÇÃO}

As relações sociais podem viabilizar a criação de redes para atender necessidades de indivíduos e grupos. As redes sociais são formadas por pessoas que compartilham crenças, conhecimento e prestígio com interesses comuns. Elas representam uma das estratégias de Gestão do Conhecimento usadas pelas corporações para compartilhar informações e desenvolver conhecimento através das relações entre seus participantes (TOMAÉL et al., 2005). As corporações podem ser entendidas como redes sociais que reúnem pessoas para efetivar negócios e atingir metas organizacionais (CHO; CHAN, 2008). As redes sociais corporativas focalizam as interações sociais de pessoas com interesses comerciais para sobreviver e ganhar vantagem competitiva.

As redes sociais mediadas por computador podem gerar fluxos de informação e novos intercâmbios sociais (RECUERO, 2009). 0 estudo destas interações no ambiente organizacional é importante para o reconhecimento das fontes de informação, de criação, recuperação e manutenção do conhecimento organizacional (LEON et al., 2017). 
A apreciação do conhecimento provocou uma revolução tecnológica na qual a centralização de dados e informações não é suficiente; também é necessário aplicá-los e gerar conhecimento por meio de dispositivos tecnológicos (CASTELLS, 1999). Atualmente, a tecnologia da informação realiza muitas das operações cognitivas anteriormente realizadas por pessoas, como armazenamento, recuperação e conexão de informações em atividades de conhecimento (SIGALA; CHALKITI, 2015; KANE, 2017). Portanto, Investimentos em sinergia via web podem ser multiplicados pelo desenvolvimento de redes digitais.

Analisar e compreender o fenômeno das redes, bem como a evolução econômica dos grupos e organizações sociais, são essenciais para acessar, interpretar e aplicar a informação disponível (BROOKES et al., 2006). Torna-se necessário compreender o processo de globalização social apoiado pela informação e seu impacto no processo de Gestão do Conhecimento.

O objetivo deste artigo é identificar como a Gestão do Conhecimento e as Mídias Sociais estão relacionadas na literatura científica para encorajar futuras pesquisas. As premissas conceituais sobre Gestão do Conhecimento e Mídias Sociais são apresentadas. 0 método de mapeamento do conhecimento científico intitulado Knowledge Development Process Constructivist - ProKnow-C é a metodologia sugerida para análise bibliométrica e sistêmica de literatura em bases de dados de conhecimento científico confiável. O Prokwnow- $C$ viabilizou a busca, a organização e a categorização de fontes de dados para incentivar pesquisas futuras.

\section{GESTÃO DO CONHECIMENTO (GC) E MÍDIAS SOCIAIS (MS)}

O conhecimento é uma fonte de vantagem competitiva e a Gestão do Conhecimento (GC) tem sido entendida como atividades de conhecimento corporativo para alcançar objetivos organizacionais (ZHANG et al., 2015). GC para criar vantagem competitiva por inovações é um tópico amplamente explorado na literatura científica (NONAKA; TAKEUCHI, 1997, PAN; SCARBROUGH, 1999; NONAKA; VON KROGH, 2009; VON KROGH, 2012; SIGALA; CHALKITI, 2015). Nonaka e Takeuchi (1997, p.12) definem GC como "a habilidade de uma empresa criar conhecimento, disseminá-lo na organização e incorporá-lo em produtos, serviços e sistemas". Esta definição é adotada neste artigo porque destaca o papel da GC em um ambiente corporativo estratégico. Além disso, a definição envolve questões sobre a conversão de conhecimento tácito apoiado por sistemas e ferramentas inovadoras.

GC é um conjunto de processos pelos quais a organização mantém ou melhora seu desempenho estratégico com base na experiência e no conhecimento (PAN; SCARBROUGH, 1999). O conhecimento é um fator estratégico relacionado aos processos de negócios para atender diretrizes da empresa (VON KROGH, 2012). As organizações são desafiadas a identificar e formalizar informações estratégicas (BERNUS; KALPIC, 2006). 0 alinhamento entre GC e planejamento estratégico viabiliza desenvolver organizações que usam o conhecimento lucrativo para efetivar suas operações (LAM et al., 2016).

Nonaka e von Krogh (2009) destacam a visão social da GC. O equilibrio entre rotinas, criações e inovações deve ser observado e incentivado nos dispositivos da empresa. 0 conhecimento, a inovação e a criatividade são fatores competitivos para apoiar e promover a adaptação, a sobrevivência e o excelente desempenho de uma empresa (SIGALA; CHALKITI, 2015). Para que esses fatores vantajosos sejam evidenciados, as organizações podem implementar estratégias de GC juntamente com estratégias corporativas.

Os processos sociais, as redes sociais e o capital social têm um papel efetivo em projetos de GC (BROOKES et al., 2006). As intervenções devem basear-se em processos, padrões e práticas sociais como redes sociais e ferramentas de mídia social. Dentro do panorama da participação coletiva, uma rede social é definida como um conjunto de pessoas, instituições ou grupos e suas interações sociais (RECUERO, 2009; LEON et al., 2017). As conexões inerentes a este ambiente possibilitam compartilhar e atingir objetivos comuns (ALCARÁ et al., 2006). Quando planejada estrategicamente, a rede social corporativa é uma ferramenta de competitividade empresarial, pois fornece uma visão sistêmica da informação.

Para beneficiar-se da GC, é necessário utilizar métodos e tecnologias adequados à evolução das relações existentes nas organizações, tanto entre funcionários como entre os envolvidos na cadeia de valor (PORTER; MILAR, 1985). Esses relacionamentos são influenciados pelas mídias sociais que causam mudanças nas formas de compartilhamento do conhecimento (BEBENSEE et al., 2011). Neste contexto, Mídias Sociais (MS) são um conjunto

Revista Alcance - Eletrônica - vol. 24 - n. 2 - abr.jjun. 2017 
de ferramentas para comunicação entre pessoas conectadas em um ambiente Web 2.0 (O'REILLY, 2005). Assim, as ferramentas de MS facilitam o trabalho coletivo.

As redes sociais on-line funcionam como um mecanismo tecnológico para o gerenciamento de relacionamentos em sistemas de GC (PAN et al., 2015). Como plataforma e meio de disseminação de informação, as MS permitem agregar, compartilhar, armazenar e sintetizar conhecimento de várias fontes para a criação de novas soluções.

A Web 2.0 tem três camadas de relevância para a GC: é baseada em princípios sociais, produção coletiva e colaboração sem fronteiras; é um conjunto intuitivo de aplicativos fáceis de usar e baseia-se em plataformas de código aberto as quais permitem serviços para economias de escala (BEBENSEE et al., 2011). Os gerentes podem capturar o conhecimento informal em redes sociais e aprender sobre como interagir para colaborar em grupos de trabalho (RICHARDS, 2009). Os softwares de MS desafiam o pensamento estratégico para a criatividade, independência e desempenho em ambientes incertos, porque ajudam a converter parte do conhecimento tácito em conhecimento explícito (HAEFLIGER et al., 2011).

As MS podem ter impacto na estrutura das organizações. Aquelas que adotam o conceito de negócio colaborativo baseiam-se na promoção de comunidades internas e externas por meio de ferramentas da web com funções sociais e alinhamento às necessidades das empresas (CHRISTIDIS et al., 2012). $O$ uso adequado de redes em ambientes corporativos estimula práticas de compartilhamento de conhecimento (CHOW; CHAN, 2008; PILLET; CARILLO, 2016). Esse é o papel da Enterprise 2.0 focada na promoção interna, nas comunidades externas e em ferramentas sociais da Web alinhadas às necessidades do negócio (CHIRISTIDIS et al., 2015).

Este panorama da relação entre GC e MS aponta para uma visão estratégica do conhecimento em organizações apoiadas pelo uso de ferramentas da web. A seguir, a metodologia utilizada neste estudo será descrita.

\section{BUSCA POR INFORMAÇÕES CONFIÁVEIS: KNOWLEDGE DEVELOPMENT PROCESS CONSTRUCTIVIST - PROKNOW-C}

Durante a busca de publicações para revisão de literatura sobre um tema de estudo, encontra-se um universo de informações dispersas (TASCA et al., 2010). Com a grande quantidade de informações, o pesquisador pode colocar de lado a literatura relevante, enquanto se concentra em textos menos respeitáveis e pode comprometer o resultado de sua pesquisa. Torna-se necessário selecionar apenas uma parte do conteúdo disponível para construir o conhecimento sobre um tema de pesquisa de forma abrangente e eficiente.

Assim, propõem-se a seguir as etapas do Proknow- $C$, desenvolvido por pesquisadores do Laboratório de Metodologias Multicritério de Apoio à Decisão da Universidade Federal de Santa Catarina (LabMCDA). O ProKnow-C permite mapear o conhecimento científico sobre um tema de estudo e suas fronteiras, verificar a acessibilidade aos meios de disseminação da pesquisa por meio de um processo sistemático (ENSSLIN et al., 2010). A ferramenta orienta o pesquisador a identificar pontos fortes e lacunas no conhecimento sobre o tema analisado (LACERDA et al., 2011). A Figura 1 resume o processo do ProKnow-C para mapear informações científicas respeitáveis. 
Figura 1: ProKnow-C

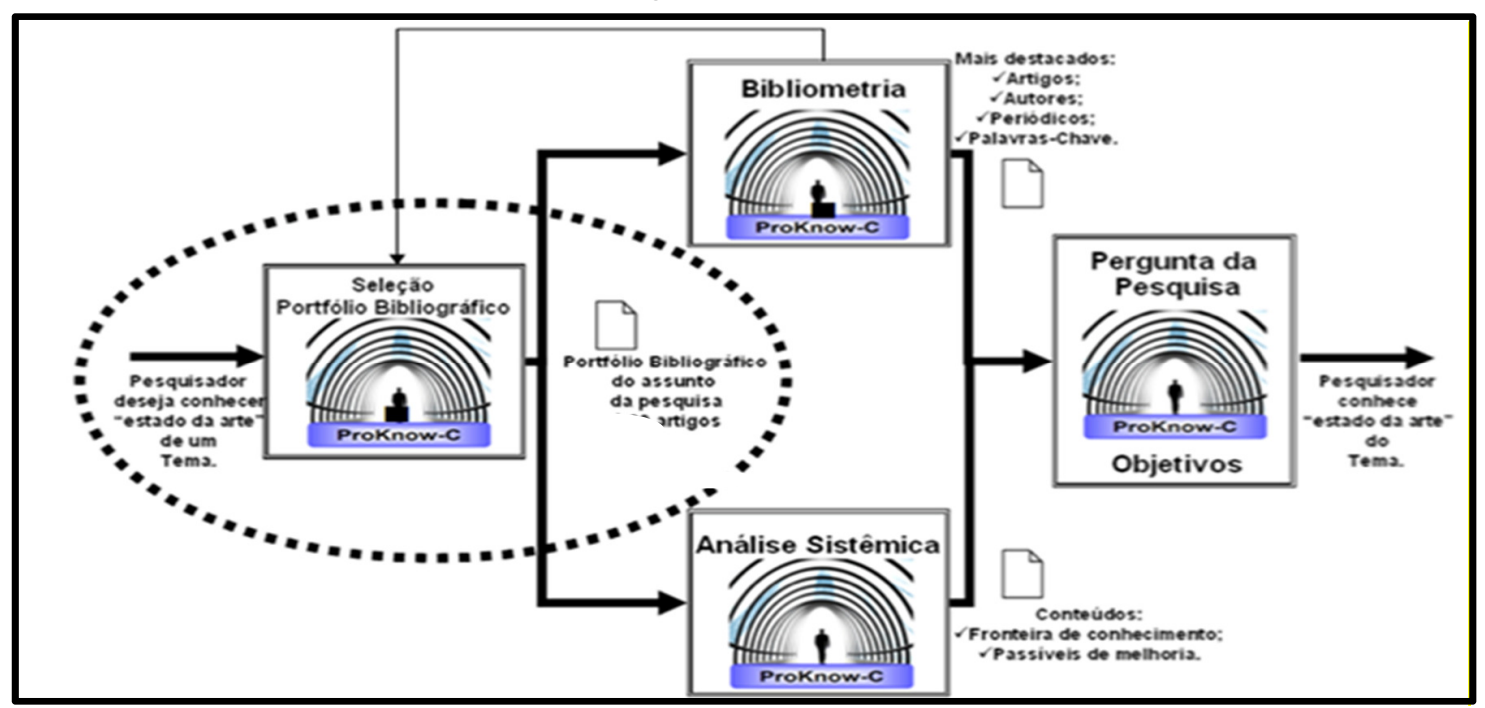

Fonte: Enssilin et al. (2010).

O ProKnow-C envolve as seguintes etapas: (a) Seleção do portfólio bibliográfico - compilação de publicações com reconhecimento científico e proeminência, com título, conteúdo do resumo e conteúdo completo alinhado ao tema de estudo de acordo com a percepção e os limites do investigador; (b) Bibliometria - divulgação quantitativa do processo de coleta de dados estatísticos do conjunto de artigos (portfólio bibliográfico) para a gestão da informação e do conhecimento científico sobre o assunto; (c) Análise Sistêmica - análise de uma amostra representativa de itens de uma determinada pesquisa, visando evidenciar os destaques e as lacunas teóricas encontradas para cada conceito.

A seleção do portfólio será apresentada na próxima seção. A análise bibliométrica e sistêmica compreende os resultados deste estudo.

\subsection{Seleção do Portifólio Bibliográfico}

Esta fase, neste estudo, consistiu na seleção de um portfólio bibliográfico com publicações relevantes relacionadas ao tema "GC e MS". A partir das pesquisas em banco de dados, foi criado um portfólio de artigos para compor a base bibliográfica da pesquisa. A Figura 2 mostra os passos para selecionar o portfólio bibliográfico. 
Figura 2: Seleção do portfólio bibliográfico

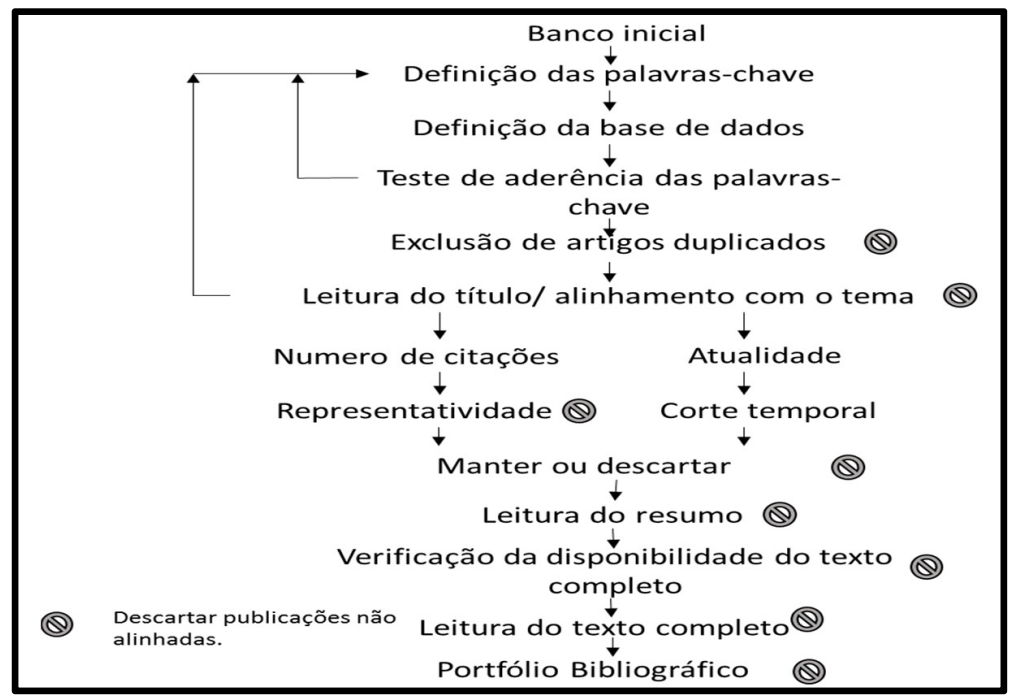

Fonte: Adaptada de Enslinn et al. (2010).

As seis subetapas da formação do portfólio bibliográfico serão descritas a seguir.

\subsubsection{Seleção prévia do banco de artigos}

O espaço amostral foi definido entre as bases de dados disponibilizadas pela Coordenação de Aperfeiçoamento de Pessoal do Ensino Superior (CAPES), por reunir as principais bases de dados científicos do mundo e pela disponibilidade e pelo reconhecimento científico no Brasil.

\subsubsection{Definição das palavras-chave}

Uma pesquisa não estruturada foi realizada por títulos vinculados ao tópico "GC e MS" na ferramenta Google Acadêmico. Os artigos sobre o tema foram selecionados e as palavras-chave relacionadas ao assunto foram identificadas. Foram selecionadas as seguintes palavras-chave: gestão do conhecimento, redes sociais empresariais; mídias sociais, intranet social, rede social, sites de redes sociais, software social. Para realizar a busca por artigos no banco de dados, foi necessário usar combinações de palavras-chave (Figura 3).

Figura 3: Combinações de palavras-chave

\begin{tabular}{|c|c|}
\hline Eixo 1 & \multicolumn{1}{c|}{ Eixo 2} \\
(a) "knowledge management" & $\begin{array}{l}\text { (b) "enterprise social network } \\
\text { (c) "social media" } \\
\text { (d) "social intranet" } \\
\text { (e) "social network" } \\
\text { (f) "social networking sites" } \\
\text { (g) "social software" }\end{array}$ \\
\hline AND
\end{tabular}

Fonte: Autores. 
A relação entre os dois eixos de pesquisa da Figura 3 resultou em seis combinações (ab, ac, ad, ae, af e ag), sempre usando a palavra-chave do eixo de busca 1 (a), o operador booleano "AND" e o segundo eixo de busca (b) até (g). Após este teste inicial, as mesmas combinações foram utilizadas para buscar publicações na base determinada para investigar o tema em estudo.

\subsubsection{Determinação da base de dados}

A Science Direct foi a base de dados determinada para a presente investigação por (a) disponibilidade de artigos, (b) acessibilidade a todos os artigos pesquisados, (c) integração com o software EndNote ${ }^{\circledR}$ e (d) possibilitar a aplicação dos filtros de pesquisa.

\subsubsection{Busca de artigos na base de dados}

Dois filtros de busca foram definidos, a saber: abordagem do estado recente do tema (de janeiro de 2005 a fevereiro de 2017) e artigos de periódicos em inglês. A pesquisa de artigos nas bases de dados foi efetuada em revistas científicas, nos campos título, resumo e palavras-chave (conforme a Figura 3). Os arquivos foram importados em formato "RIS", com o objetivo de gerenciar as referências no aplicativo EndNote ${ }^{\circledR}$.

\subsubsection{Teste de adesão das palavras-chave}

Nesta etapa foram selecionadas palavras-chave para assegurar que o conteúdo dos artigos fosse representativo do tema. Os títulos foram pesquisados até encontrar dois artigos alinhados com o tema da pesquisa. Os artigos selecionados e as respectivas palavras-chave estão no Quadro 1.

Quadro 1: Artigos selecionados para o teste de adesão

\begin{tabular}{|c|l|l|}
\hline \multicolumn{1}{|c|}{ Autor } & \multicolumn{1}{|c|}{ Título do artigo } & \multicolumn{1}{c|}{ Palavras-chave } \\
\hline Brookes et al. & $\begin{array}{l}\text { Social processes, patterns and practices and } \\
\text { project Knowledge Management: A theoretical } \\
\text { framework and an empirical investigation }\end{array}$ & $\begin{array}{l}\text { Individuals; Teams; Managing projects; } \\
\text { HRM; Knowledge Management; Social } \\
\text { capital; Social networks }\end{array}$ \\
\hline Monclar et al. & $\begin{array}{l}\text { MEK: Using spatial-temporal information to } \\
\text { improve social networks and knowledge } \\
\text { dissemination }\end{array}$ & $\begin{array}{l}\text { CSCW; Knowledge Management; Mobile } \\
\text { computing; Distributed collaboration; Social } \\
\text { networks }\end{array}$ \\
\hline
\end{tabular}

Fonte: Autores.

A relação entre as palavras-chave encontradas nos dois artigos citados no Quadro 1 e as palavras citadas na Figura 3 foi conduzida para verificar se elas eram semelhantes, se havia a necessidade de incorporá-las ou alterá-las. Observou-se que, nos dois artigos, algumas palavras-chave se sobrepõem. Após o teste de adesão, observou-se que as palavras selecionadas podem representar as referências publicadas nas bases de dados acadêmicas para a pesquisa.

\subsubsection{Filtragem do banco de dados}

Foram aplicados filtros em relação à redundância, ao alinhamento com o título, ao reconhecimento científico e à padronização integral do texto. As referências importadas no $E n d N o t e^{\circledR}$ foram organizadas em grupos para permitir sua gestão. As referências repetidas foram eliminadas. Obteve-se um total de 429 referências. Os artigos foram classificados por título, lidos em sequência e eliminados aqueles que não estavam alinhados com o tema de pesquisa. No final, após a leitura dos títulos e resumos, foram eliminados 387 artigos. Restaram penas 42 estudos alinhados com o tema. 


\subsection{Critérios para Análise Sistêmica}

No presente estudo, assume-se que a análise sistêmica é um processo científico para analisar o portfólio bibliográfico de um determinado tópico de pesquisa (ENSSLIN et al., 2010). 0 objetivo da análise é mostrar, para cada critério e globalmente, os destaques e as oportunidades para pesquisas futuras. Os critérios adotados para realizar a análise sistêmica, neste estudo, são descritos no Quadro 2.

Quadro 2: Critérios para Análise Sistêmica

\begin{tabular}{|l|l|}
\hline \multicolumn{1}{|c|}{ Critério } & \multicolumn{1}{c|}{ Conteúdo } \\
\hline Conceitos & Conceitos relacionados à “GC e MS" nos estudos selecionados. \\
\hline Metodologias & Procedimentos metodológicos utilizados para conduzir os estudos. \\
\hline Resultados & Principais resultados teóricos e empíricos dos estudos. \\
\hline Oportunidades de pesquisas & Oportunidades de pesquisas para continuidade dos estudos. \\
\hline
\end{tabular}

Fonte: Autores.

\section{INCENTIVANDO PESQUISAS FUTURAS}

Este item abrange os principais resultados do estudo para encorajar pesquisas futuras sobre "GC e MS". Em primeiro lugar, uma análise bibliométrica sobre o tema "GC e MS" identifica o portfólio de artigos; o estado atual da pesquisa sobre o tema; a concentração da maior porcentagem de publicações e as revistas que mais publicaram sobre tema entre janeiro de 2005 e fevereiro de 2017. Em segundo lugar, foi realizada uma análise sistêmica, que consistiu em uma discussão dos conceitos principais, metodologias, resultados e oportunidades de pesquisa. 0 número de publicações por ano é evidenciado no Gráfico 1.

Gráfico 1: Publicações por ano

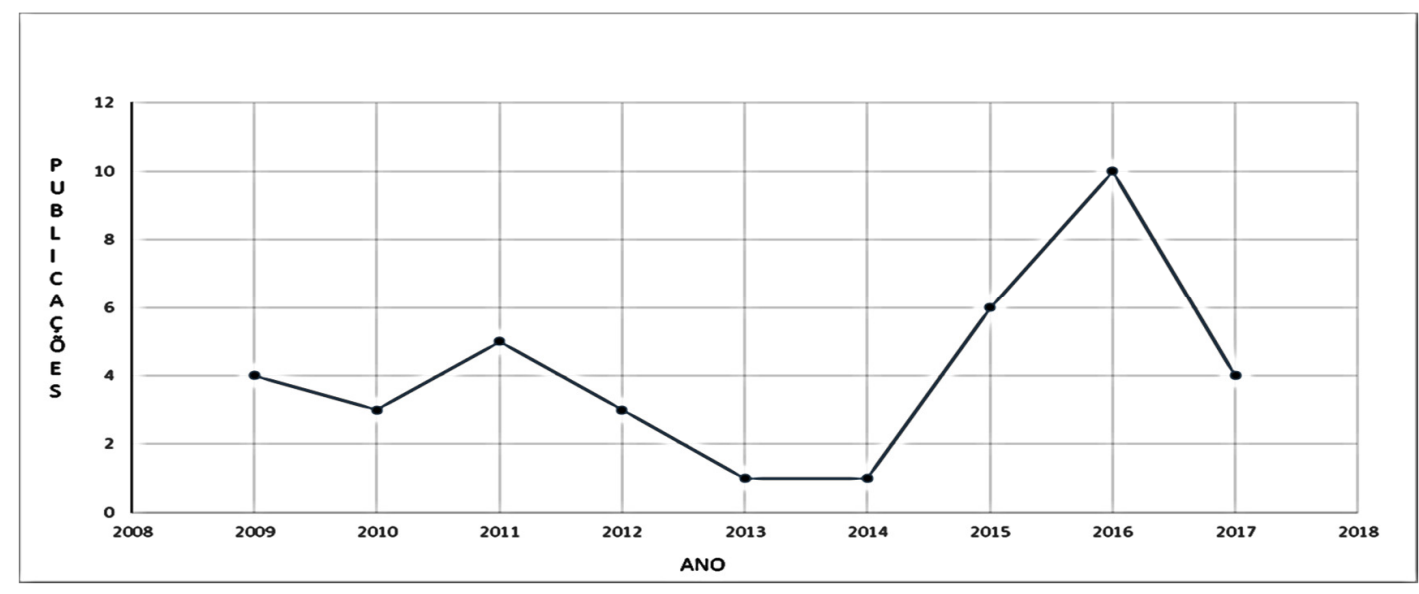

Fonte: Autores.

O estudo de "MS" no âmbito da "GC" é recente. Entre os 42 artigos, 25 foram publicados de janeiro de 2012 a fevereiro de 2017. Portanto, cerca de $60 \%$ dos artigos do portfólio foram publicados nos últimos anos. A Tabela 1 exibe uma classificação das 6 principais revistas que publicaram sobre "GC e MS" de janeiro de 2005 a fevereiro de 2017. Cada uma das outras revistas apresentou uma publicação. $O$ total é de 27 revistas. 
Tabela 1: Principais Periódicos

\begin{tabular}{l|c}
\multicolumn{1}{c|}{ Periódico } & Publicações \\
\hline Computers In Human Behavior & 06 \\
\hline Expert Systems With Applications & 04 \\
\hline International Journal of Information Management & 04 \\
\hline Information \& Management & 03 \\
\hline Business Horizons & 02 \\
\hline Information Sciences & 02 \\
\hline
\end{tabular}

Fonte: Autores.

Computers in Human Behavior aparece em primeiro lugar com 06 publicações. Expert Systems with Applications e International Journal of Information Management estão em segundo lugar com 04 publicações cada um. Business Horizons e Information Sciences com 02 publicações estão em terceiro lugar. Estes resultados demonstram que a maioria das publicações está concentrada em algumas revistas. Os principais periódicos investigam questões relacionadas ao comportamento humano, computadores, aplicação de sistemas e gerenciamento de informações. Esta constatação aponta para o alinhamento do tema nas revistas mais relevantes quanto ao número de publicações.

\subsection{Análise Sistêmica}

Nos itens a seguir são relatados os resultados da análise sistêmica. Os principais conceitos identificados são discutidos. Os resultados observados no estudo são analisados. 0 quarto critério tem o objetivo de demonstrar futuras oportunidades de pesquisa.

\subsubsection{Conceitos principais}

O Quadro 3 sumariza os principais conceitos e respectivas definições retirados do portfólio de artigos.

Quadro 3: Conceitos e definições

\begin{tabular}{|l|l|}
\hline \multicolumn{1}{|c|}{ Conceitos } & \multicolumn{1}{c|}{ Definições } \\
\hline Conhecimento & Fonte de vantagem competitiva organizacional. \\
\hline Gestão do Conhecimento & Atividades para atingir objetivos organizacionais por meio do uso do conhecimento. \\
\hline $\begin{array}{l}\text { Difusão do conhecimento } \\
\text { inovador }\end{array}$ & Forma de ação coletiva que requer organização social. \\
\hline Comunidades de Prática & Ambientes em que o conhecimento tácito pode ser compartilhado. \\
\hline Redes Sociais & $\begin{array}{l}\text { Grupos formados na sociedade por interesses comuns ou pensamentos } \\
\text { semelhantes. Redes de informação que retratam as interações entre indivíduos ou } \\
\text { entidades. }\end{array}$ \\
\hline Mídias Sociais & $\begin{array}{l}\text { Plataformas através das quais a socialização de interesses e de pensamentos } \\
\text { comuns torna-se possível. Aplicativos baseados na Web orientados com base na } \\
\text { Web 2.0 para a criação e intercâmbio de informação de forma colaborativa. }\end{array}$ \\
\hline Software Social & $\begin{array}{l}\text { Software que permite às comunidades compartilhar conhecimento experiencial para } \\
\text { informar pessoas e grupos e permitir que tirem suas próprias conclusões. Filtros de } \\
\text { informação que auxiliam na tomada de decisões rápidas e na resolução eficaz de } \\
\text { tarefas estratégicas. Todos os sistemas que permitem interaçôes sociais e } \\
\text { aumentam a conectividade entre os participantes. }\end{array}$ \\
\hline
\end{tabular}




\begin{tabular}{|l|l|}
\hline $\begin{array}{l}\text { Plataformas de comunicação } \\
\text { social }\end{array}$ & Filtro de informação e conhecimento que facilita a mudança organizacional. \\
\hline Rede Social Corporativa & $\begin{array}{l}\text { Um ambiente de ferramentas de mídia social: fóruns, blogs, wikis, comunidades, } \\
\text { microblogs, podcasts, entre outros, para apoiar uma organização a atingir suas } \\
\text { metas. }\end{array}$ \\
\hline Web 2.0 & $\begin{array}{l}\text { Modo de comunicação na Internet cujos desenvolvedores de software e usuários da } \\
\text { World Wide Web podem modificar o conteúdo compartilhado. }\end{array}$ \\
\hline Empresas 2.0 & $\begin{array}{l}\text { Empresas que adotam estratégia de utilização de práticas sociais e ferramentas } \\
\text { alinhadas com suas necessidades de negócio. }\end{array}$ \\
\hline Cultura Cibernética & $\begin{array}{l}\text { Processo que envolve pessoas e propósitos comuns em um ambiente de conexão } \\
\text { generalizada. }\end{array}$ \\
\hline $\begin{array}{l}\text { Capital em ambientes } \\
\text { virtuais }\end{array}$ & $\begin{array}{l}\text { Soma dos recursos derivados das relações nas redes e obtidos pela comunidade } \\
\text { virtual. }\end{array}$ \\
\hline $\begin{array}{l}\text { Compartilhamento } \\
\text { Colaborativo }\end{array}$ & $\begin{array}{l}\text { Processo de desenvolvimento de tecnologias e organização de informações } \\
\text { apoiadas em conhecimento explícito. }\end{array}$ \\
\hline $\begin{array}{l}\text { Etiquetagem social } \\
\text { colaborativa }\end{array}$ & Modelo conceitual personalizado para indexação da base do conhecimento coletivo. \\
\hline Sistemas de Recomendação & $\begin{array}{l}\text { Recursos que oferecem informações aos funcionários de uma empresa para usar } \\
\text { novas tecnologias com base nas necessidades e nas preferências dos usuários. }\end{array}$ \\
\hline
\end{tabular}

Fonte: Autores.

A difusão do conhecimento inovador é uma forma de ação coletiva que requer organização social (VAN BAALEN et al., 2005). A disseminação do conhecimento é vista como um processo interativo que inclui a participação de diferentes atores. Para Takaffoli et al. (2011), as redes sociais retratam as interações entre indivíduos ou organizações. Cada indivíduo é representado por um nó na rede. As interações entre indivíduos formam laços entre nós e possibilitam o aumento do conhecimento sobre o desempenho organizacional (KWAHK; PARK, 2016).

Comunidades práticas se destacam entre as redes sociais. Elas são dispositivos de aprendizagem em ambientes cujo conhecimento tácito pode ser compartilhado livremente (ANTONIOUS et al., 2015; PAN et al., 2015; SCOTT et al., 2016). O software social pode facilitar vários tipos de comunidades virtuais práticas.

O desenvolvimento de intervenções baseadas em processos, práticas e padrões de conhecimento social é fator estratégico para melhorar o desempenho organizacional (LAM et al., 2016). A GC necessita de sistemas e aplicativos compatíveis com as tarefas de captura, aquisição, organização e comunicação de conhecimento entre os funcionários para torná-los mais produtivos. Como as tecnologias mais recentes envolvem redes sociais, é essencial que 0 compartilhamento colaborativo seja baseado em MS (ANTONIOUS et al., 2015).

As redes sociais podem ser incluídas entre as MS, mas não devem ser consideradas sinônimos (KAPLAN; HAENLEIN, 2010). As redes são grupos formados na sociedade por interesses comuns ou pensamentos semelhantes. MS são plataformas através das quais a socialização desses interesses e pensamentos torna-se possível. MS significa produção descentralizada de conteúdos (KAPLAN; HAENLEIN, 2010). Diferentemente do sistema de comunicação de massas, a produção de conhecimento em MS acontece por todos, para todos e em todas as direções, afetando a GC organizacional (KANE, 2017).

As MS estão mudando a forma como as pessoas buscam informação, compartilham e comunicam conhecimento (KIM et al., 2011). Elas acontecem no ambiente da cibercultura (MONCLAR et al., 2009), que envolve pessoas e propósitos comuns em um espaço de conexão generalizada.

As plataformas de comunicação social podem ser percebidas como mediadoras entre grupos de usuários e suas respectivas funções. Elas são como um filtro de informação e conhecimento e um facilitador da mudança organizacional (HAEFLIGER et al., 2011; VON KROGH, 2012). 
Os grupos que interagem com a organização se tornam cocriadores de atividades organizacionais (HANNA et al., 2011). Portanto, as redes sociais são uma solução eficiente para apoiar a GC, tornando-se um novo foco de pesquisa e uma tendência de mercado (PIRKKALAINEN; PAWLOWSKY, 2014).

Um número crescente de organizações implementou blogs, wikis, redes internas e outras ferramentas para facilitar 0 intercâmbio de conhecimento entre os funcionários (BEHRINGER; SASSEMBERG, 2015). Todas as ferramentas e as tarefas das redes corporativas buscam assegurar o sucesso organizacional e a competitividade (ARGOTE; FAHRENKOPF, 2016). Se houver uma constante troca e volume de negócios na empresa, é necessário apoio para que os novos funcionários busquem referências (BEHRINGER; SASSEMBERG, 2015)

Uma rede social corporativa é um ambiente dotado de ferramentas de MS: fóruns, blogs, wikis, comunidades, microblogs, podcasts, entre outras, para auxiliar uma organização no cumprimento de seus objetivos (SENNA, 2008). As redes sociais podem facilitar a partilha de conhecimento tácito se a frequência de interação e a proximidade dos utilizadores forem elevadas. $O$ conhecimento compartilhado, se usado corretamente, impacta o desempenho do negócio (JANHONEN; JOHANSON, 2011). Por meio da análise das relações entre as pessoas nas redes sociais, pode-se identificar o fluxo de conhecimento, bem como as pessoas chave para o excelente desempenho dos negócios (LEON et al., 2017).

Quando os usuários produzem conhecimento em sites de redes sociais, muitos fatores afetam seu comportamento de partilha. As características sociais e ambientais também influenciam sua conduta e devem ser consideradas em projetos de GC (CHAl; KIM, 2012).

Um dos conceitos-chave para entender a dinâmica da formação de redes digitais colaborativas é a Web 2.0. 0 termo foi usado pela primeira vez por O'Reilly (2005) para descrever um modo de comunicação pela internet que permitia aos desenvolvedores de software e usuários apoiarem-se na World Wide Web como uma plataforma em que o conteúdo e as aplicações são continuamente modificados por todos. Neste cenário, as MS constituem aplicações baseadas na Web, e permitem criação e troca de informações de forma livre e colaborativa (KAPLAN; HAENLEIN, 2010; CHEN, 2013; PILLET; CARILLO, 2016).

Os softwares que permitem essas atividades, chamados Enterprise Social Softwares, usam tecnologias Web 2.0 para incentivar a participação por interações informais. O software social pode ser qualquer sistema que permite interações sociais e aumenta a conectividade entre os participantes (GAO et al., 2010). Estes softwares usam um conjunto de ferramentas como blogs, wikis, feeds, sistemas de distribuição de conteúdo, aplicativos de bookmarking social e fóruns de discussão, entre outros necessários para habilitar a GC (CHRISTIDIS et al., 2012).

Por meio de sistemas tecnológicos para organização da informação em MS, as grandes empresas obtêm melhores resultados (KANE, 2017). Os sistemas são apoiados em informações organizadas e sustentadas no conhecimento explícito. Pequenas e médias empresas têm grande parte do seu conhecimento centrado num pequeno grupo de pessoas, tornando mais rápido e simples o processo de captura do conhecimento em MS (ATRASH, 2015).

As empresas 2.0 adotam práticas e ferramentas alinhadas com suas estratégias de negócios. Elas incentivam a participação de comunidades internas e externas utilizando ferramentas web com funções sociais para entender 0 comportamento de usuários e tomar ações voltadas para melhorar o desempenho dos negócios (CHRISTIDIS et al., 2012).

Para fazer essa conexão no ambiente organizacional corporativo, é preciso criatividade, um processo social e comunicativo apoiado por elementos de GC. Na cultura cibernética, a relação virtual entre as pessoas é um destaque, pois o processo de criação individual não é mais suportado (SIGALA; CHALKITI, 2015).

Em ambientes virtuais, o capital é a soma dos recursos disponíveis derivados dos relacionamentos em redes midiáticas e obtidos pelas experiências da comunidade virtual (BROOKES et al., 2006). A abordagem para o uso de MS deve ser integrada, uma vez que a mídia digital não substitui a mídia tradicional (HANNA et al., 2011).

A etiquetagem social corporativa, além de permitir a produção e o compartilhamento de conteúdo, dá ao usuário a oportunidade de classificar as informações de acordo com seus próprios padrões. Este processo de indexação de informação resulta no agrupamento de recursos similares por meio do envolvimento da comunidade. Permite a criação de um vocabulário comum e reflete um modelo conceitual personalizado. A etiquetagem social colaborativa incentiva 
a participação na marcação de várias informações (documentos, fotografias, vídeos, mapas, textos, etc.), e contribui para o trabalho individual e indexação da base de conhecimentos coletivos (KAKALI; PAPATHEODOROU, 2010).

$O$ uso de sistemas de recomendação (KIM et al., 2011), a fim de apoiar os funcionários de uma empresa a utilizar novas tecnologias (BEHRINGER; SASSENBERG, 2015; KANE, 2017), é um recurso baseado nas características, nas preferências e nas necessidades do usuário. No entanto, devido ao nível de interação com outros sistemas, é necessário analisar riscos de implantação (JUNG, 2009).

Sistemas especialistas captam conhecimento explícito para fornecer classificações dentro de uma área restrita. Esta abordagem está em conflito com a utilizada pelo software social, que permite que as comunidades compartilhem conhecimento tácito de forma mais prática ou experimental para informar as pessoas, os grupos e permitir que retirem suas próprias conclusões (RICHARDS, 2009).

As redes sociais são soluções de apoio à GC, tornando-se um novo foco de pesquisa e uma tendência de mercado (PIRKKALAINEN; PAWLOWSKY, 2014). Entretanto, a experiência real dos indivíduos e dos grupos nas redes sociais corporativas é essencial na receptividade da informação publicada (SHANG et al., 2017).

Esta discussão dos conceitos descritos no Quadro 3 indica que a relação entre "GC" e "MS" envolve diversas definições derivadas das ciências sociais, ciência da informação, tecnologia da informação, dentre outras áreas do conhecimento. A diversidade de definições para redes sociais, mídias sociais e software social foi destacada, além dos conceitos periféricos que envolvem o tema em estudo. Pode-se avaliar que as mídias sociais denotam um desafio para investigar novas formas e dispositivos para a GC.

\subsubsection{Metodologias}

As metodologias identificadas no portfólio foram classificadas por natureza do estudo e tipo de procedimento (Tabela 2).

Tabela 2: Metodologias

\begin{tabular}{l|c|l|c}
\multicolumn{5}{c}{ Metodologias } \\
\hline \multicolumn{1}{c|}{ Natureza } & Frequência & \multicolumn{1}{|c}{ Métodos } & Frequência \\
\hline Empírico & 20 & Estatísticos & 19 \\
\hline Teérico & 11 & Análise de Conteúdo & 9 \\
\hline Ambos & 11 & Estudos de Caso & 7 \\
\hline \multirow{4}{*}{ TOTAL } & Experimentos & 3 \\
\cline { 2 - 4 } & Simulação & 2 \\
\cline { 2 - 4 } & Pesquisa Participativa & 1 \\
\cline { 2 - 4 } & Modelo Semântico & 1 \\
\hline
\end{tabular}

Fonte: Autores.

A Tabela 2 mostra que foram encontrados 20 estudos empíricos, ou seja, cerca de 48\%, bem como 11 artigos teóricos e empíricos, com cerca de $26 \%$ e $26 \%$ de estudos teóricos. Portanto, há uma lacuna de artigos teóricos sobre "GC" " "MS". Métodos de estatísticos compreendem 45\%; seguidos de análise de conteúdo, com cerca de 21\%, e estudos de caso, com cerca de $17 \%$ do total. Os outros métodos apresentam uma frequência entre $7 \%$ e $2 \%$. Métodos quantitativos são os mais utilizados para estudar "GC e MS". Portanto, existem lacunas para realizar mais pesquisas com estudos qualitativos e métodos mistos.

\subsubsection{Resultados principais}

O objetivo deste item é apresentar os principais resultados encontrados nos estudos do portfólio selecionado. 
O Quadro 4 lista os resultados em ordem crescente de publicação.

Quadro 4: Resultados principais

\begin{tabular}{|c|c|c|}
\hline Ano & Autores & $\begin{array}{c}\text { Resultados Principais } \\
\end{array}$ \\
\hline 2005 & van Baalen et al. & $\begin{array}{l}\text { A utilização de um portal ajudou a superar problemas estruturais e comprometimento } \\
\text { cognitivo entre projetos. }\end{array}$ \\
\hline 2006 & Brookes et al. & $\begin{array}{l}\text { Confiança, respeito, longevidade de relacionamentos, compartilhamento de experiências } \\
\text { profissionais, educacionais e contextos amplos são conceitos-chave para o } \\
\text { desenvolvimento de projetos de GC. }\end{array}$ \\
\hline 2007 & Matsuo et al. & $\begin{array}{l}\text { A arquitetura para identificação e extração das relações propostas permite obter redes } \\
\text { sociais mais precisas. }\end{array}$ \\
\hline 2008 & Sena e Sena & $\begin{array}{l}\text { Uma estratégia de redes sociais bem concebida deve ser capaz de respeitar as relações } \\
\text { individuais e manter o anonimato relativo. }\end{array}$ \\
\hline \multirow{4}{*}{2009} & Jung & $\begin{array}{l}\text { As decisões são tomadas de forma assertiva e com menor grau de risco de confiança no } \\
\text { tráfico de informações em uma rede social. }\end{array}$ \\
\hline & Monclar et al. & $\begin{array}{l}\text { O software ajudou a identificar o perfil dos usuários e promoveu a interação, a produção } \\
\text { e o compartilhamento de conhecimento. }\end{array}$ \\
\hline & Richards & $\begin{array}{l}\text { A abordagem fornece mecanismos para capturar conhecimento, conectar casos } \\
\text { problemáticos, identificar conflitos e resolvê-los. }\end{array}$ \\
\hline & Wi et al. & $\begin{array}{l}\text { A abordagem proposta é um método quantitativo para a seleção de pessoal adequado } \\
\text { para as equipes adequadas. }\end{array}$ \\
\hline \multirow{9}{*}{2010} & Gao et al. & $\begin{array}{l}\text { A sociabilidade e a competência do sistema podem prever } 43 \% \text { das atitudes dos usuários } \\
\text { para o software social e } 51 \% \text { dos usos previstos. }\end{array}$ \\
\hline & $\begin{array}{l}\text { Kaplan e } \\
\text { Haenlein }\end{array}$ & $\begin{array}{l}\text { Classifica as MS nos seguintes grupos: projetos colaborativos, blogs, comunidades de } \\
\text { conteúdo, sites de redes sociais, jogos virtuais e mundo social virtual. }\end{array}$ \\
\hline & $\begin{array}{l}\text { Kakali e } \\
\text { Papatheodorou }\end{array}$ & $\begin{array}{l}\text { As tags contribuem para a descrição da informação e facilitam o processo de indexação, } \\
\text { dando terminologias aos usuários de acordo com suas necessidades pessoais ou grupais } \\
\text { por meio de vocabulários dinâmicos. }\end{array}$ \\
\hline & Chi et al. & As empresas devem escolher uma rede que lhes permita receber conteúdo diversificado. \\
\hline & Haefliger et al. & $\begin{array}{l}\text { O software social facilita as interações entre os usuários e desafia não apenas a dinâmica } \\
\text { competitiva da indústria, mas também a estrutura das empresas. }\end{array}$ \\
\hline & Hanna et al. & $\begin{array}{l}\text { Combinação do tradicional com MS permite às empresas desenvolver estratégias de } \\
\text { comunicação integradas para alcançar os consumidores em um modelo multiplataforma, } \\
\text { que permite uma ampla esfera de influência. }\end{array}$ \\
\hline & $\begin{array}{l}\text { Janhonen e } \\
\text { Johanson }\end{array}$ & $\begin{array}{l}\text { A interação entre os membros da equipe, combinada com os líderes de redes } \\
\text { intraorganizacionais, contribui para o desempenho dos usuários e o impacto na GC. }\end{array}$ \\
\hline & Kim et al. & $\begin{array}{l}\text { O encaminhamento de informações através das tags pode influenciar a construção de } \\
\text { estruturas de conhecimento e a divulgação de dados de informações. }\end{array}$ \\
\hline & Takaffoli et al. & $\begin{array}{l}\text { Encontrar padrões de interação social dentro de uma rede dinâmica oferece uma ampla } \\
\text { gama de aplicativos que podem beneficiar organizações. }\end{array}$ \\
\hline \multirow{3}{*}{2012} & Chai e Kim & $\begin{array}{l}\text { A combinação de sistemas sociais e tecnológicos facilita o compartilhamento de } \\
\text { conhecimento entre os usuários. }\end{array}$ \\
\hline & Christidis et al. & $\begin{array}{l}\text { A identificação de tópicos latentes não requer uma estrutura de conhecimento explícita e } \\
\text { não depende do usuário para estruturar a categorização. }\end{array}$ \\
\hline & Von Krogh & $\begin{array}{l}\text { O conhecimento é uma fonte de vantagem competitiva das organizações, portanto deve } \\
\text { ser preservado e gera custos e riscos que podem ser mitigados com o uso de softwares } \\
\text { sociais. }\end{array}$ \\
\hline
\end{tabular}




\begin{tabular}{|c|c|c|}
\hline 2013 & Chen & | Benefícios e riscos percebidos afetam o uso de um site de rede social. \\
\hline 2014 & $\begin{array}{l}\text { Pirkkalainen e } \\
\text { Pawlowsky }\end{array}$ & \begin{tabular}{|l} 
Validação de um framework com barreiras organizacionais, sociais, técnicas e culturais para \\
o uso de software social em trabalhadores globais, que devem ser analisados em conjunto.
\end{tabular} \\
\hline \multirow{6}{*}{2015} & Antonius et al. & $\begin{array}{l}\text { As organizações que desejam implementar sistemas sociais precisam reunir uma estratégia } \\
\text { que aborda fatores individuais de usuários, fatores organizacionais, tarefas complexas, } \\
\text { cultura organizacional, estratégia de conhecimento e percepções de utilidade e facilidade } \\
\text { do sistema. }\end{array}$ \\
\hline & Atrash et al. & $\begin{array}{l}\text { A representação semântica dos grupos de usuários que compartilham conhecimento entre } \\
\text { si, além de autorizar o registro de informações relevantes e indicar as possibilidades de } \\
\text { compartilhamento. }\end{array}$ \\
\hline & $\begin{array}{l}\text { Behringer e } \\
\text { Sassenberg }\end{array}$ & $\begin{array}{l}\text { A interação entre a importância e os deficits da troca de conhecimentos, a utilidade da MS } \\
\text { e a experiência em seu uso afetam a intenção de aplicá-las à troca de conhecimento. }\end{array}$ \\
\hline & Pan et al. & $\begin{array}{l}\text { As redes sociais podem ser integradas com as comunidades de prática. Usabilidade e } \\
\text { sociabilidade são as duas dimensões fundamentais para as comunidades de prática. }\end{array}$ \\
\hline & $\begin{array}{l}\text { Sigala e } \\
\text { Chalkiti }\end{array}$ & $\begin{array}{l}\text { Há um alto nível de uso de MS para atividades de GC. Há uma lacuna nas atividades de } \\
\text { discussão, compartilhamento de informações e cocriação de conhecimento devido à } \\
\text { ausência de novas habilidades para aproveitar os benefícios das redes sociais. }\end{array}$ \\
\hline & Zhang et al. & $\begin{array}{l}\text { Os indicadores de centralidade do estudo sobre MS e GC indicam que ainda está em fase } \\
\text { inicial. }\end{array}$ \\
\hline \multirow{10}{*}{2016} & $\begin{array}{l}\text { Argoti e } \\
\text { Fahrenkopf }\end{array}$ & $\begin{array}{l}\text { A compreensão da transferência de conhecimento tem aumentado em profundidade e } \\
\text { amplitude nos últimos quinze anos. }\end{array}$ \\
\hline & Kwahk e Park & $\begin{array}{l}\text { A autoeficácia do conhecimento, os laços de interação social e a norma de reciprocidade } \\
\text { influenciam positivamente a orientação das conexões e das atividades de compartilhamento } \\
\text { de conhecimento na MS. }\end{array}$ \\
\hline & Lam et al. & As iniciativas de MS das empresas melhoram a eficiência operacional e a inovação. \\
\hline & Limaj et al. & $\begin{array}{l}\text { As capacidades dos sistemas de informação social mediam os efeitos positivos da sua } \\
\text { utilização em componentes de capacidades absortivas, que se baseiam umas nas outras e } \\
\text { mediam os efeitos positivos das capacidades de informação do sistema social na inovação. }\end{array}$ \\
\hline & $\begin{array}{l}\text { Mäntymäki e } \\
\text { Riemer }\end{array}$ & $\begin{array}{l}\text { Geração e obtenção de novas ideias para o trabalho, participar de discussões e encontrar } \\
\text { soluções são as principais fontes de valor nas redes sociais corporativas. }\end{array}$ \\
\hline & Mourtzis et al. & $\begin{array}{l}0 \text { método colaborativo de resolução de problemas baseado em redes sociais facilita o } \\
\text { compartilhamento de conhecimento e denota uma rede social voltada para os negócios. }\end{array}$ \\
\hline & Pillet e Carillo & $\begin{array}{l}\text { O uso da ferramenta de MS é influenciado positivamente pela vantagem relativa e pela } \\
\text { facilidade de uso percebida. A vantagem influencia positivamente a capacidade de } \\
\text { compartilhamento de conhecimento. }\end{array}$ \\
\hline & Scott et al. & $\begin{array}{l}\text { Existem níveis elevados de presença cognitiva e de aprendizagem nos posts recolhidos na } \\
\text { rede social empresarial. }\end{array}$ \\
\hline & Seo e Lee & $\begin{array}{l}\text { Fatores contextuais, como modelos de negócios, proposições de valor e características do } \\
\text { cliente, devem ser considerados na avaliação do desempenho organizacional da Web 2.0. }\end{array}$ \\
\hline & Villanueva et al. & $\begin{array}{l}\text { A ontologia proposta é capaz de representar o conhecimento baseado nas características } \\
\text { de produtos e usuários extraídas das MS. }\end{array}$ \\
\hline \multirow[t]{2}{*}{2017} & Kane & $\begin{array}{l}\text { As tecnologias emergentes - como a inteligência artificial e a realidade virtual - podem } \\
\text { introduzir novas mudanças no modo como as ferramentas de MS influenciam o } \\
\text { compartilhamento de conhecimento nas empresas. }\end{array}$ \\
\hline & Leon et al. & $\begin{array}{l}\text { A rede social organizacional privada é capaz de identificar líderes e seguidores e determina } \\
\text { as chances de os funcionários interagirem. }\end{array}$ \\
\hline
\end{tabular}




\begin{tabular}{|l|l|l|}
$\begin{array}{l}\text { Shang et } \\
\text { al. }\end{array}$ & $\begin{array}{l}\text { O alcance e a riqueza das plataformas de MS importam, mas de forma negativa, demonstrando efeitos } \\
\text { decrescentes quanto à partilha e à continuidade de uso e refutando a falácia "big is beautiful". }\end{array}$ \\
\hline $\begin{array}{l}\text { Whener et } \\
\text { al. }\end{array}$ & Existem vários termos usados para descrever o fenômeno das redes sociais empresariais.
\end{tabular}

Fonte: Autores.

Pode-se observar que os resultados encontrados nos estudos mencionam, em síntese, os seguintes elementos: (a) soluções, novas ideias para projetos de GC e formação de equipes; (b) conceitos-chave em projetos de GC; (c) melhoria dos processos de tomada de decisão por meio da aquisição do conhecimento sobre produtos e clientes nas MS; (d) maior confiança na informação; (e) categorização e formação de estruturas de conhecimento; (f) softwares sociais baseados em novas tecnologias como facilitadores do compartilhamento do conhecimento e fonte de vantagem competitiva das corporações; $(\mathrm{g})$ utilização combinadas das mídias tradicionais e MS para melhorar a comunicação e o compartilhamento de conhecimento nas corporações, (h) falta de novas competências dos utilizadores para tirar pleno proveito das redes sociais e mídias virtuais, (i) complexidade das MS tem efeito decrescente no compartilhamento e na continuidade do uso; e (j) necessidade de facilidade de acesso e uso das ferramentas de MS para a GC.

A busca de conhecimento sobre as interações entre os usuários, as novas ferramentas de MS em relação à confiança, à categorização, ao compartilhamento de informações e à tomada de decisões em projetos de GC são fatores a considerar. Os softwares sociais são facilitadores de vantagem competitiva nas organizações em combinação com a mídia tradicional e as tecnologias emergentes. Embora o estudo sobre "GC e MS" esteja ainda em estado inicial, a compreensão sobre transferência do conhecimento tem aumentado.

No entanto, há uma falta de estudos para verificar as possibilidades de desenvolvimento de novas competências através da aprendizagem em redes sociais eficientes. A descontinuidade de uso das MS para fins corporativos é influenciada pela sua crescente complexidade.

\subsubsection{Oportunidades de pesquisa}

Este item pretende explicitar as oportunidades de pesquisas futuras identificadas nos estudos selecionados para este trabalho. $O$ Quadro 5 expõe as oportunidades de pesquisa para encorajar estudos futuros sobre "GC e MS".

Quadro 5: Oportunidades de Pesquisa

\begin{tabular}{|c|c|c|}
\hline Ano & Autores & Oportunidades de Pesquisa \\
\hline 2005 & van Baalen et al. & Testar o estudo por meio de métodos estatísticos em larga escala. \\
\hline 2006 & Brookes et al. & $\begin{array}{l}\text { Investigações qualitativas e pesquisa-ação, mais testes quantitativos em outros } \\
\text { contextos e sobre a etiologia da conectividade em redes sociais. }\end{array}$ \\
\hline 2007 & Matsuo et al. & Validar o estudo em outros países. \\
\hline 2008 & Sena e Sena & $\begin{array}{l}\text { Investigar fatores de sucesso e fracasso do uso de redes sociais em corporações } \\
\text { em pesquisas anteriores. }\end{array}$ \\
\hline \multirow[t]{4}{*}{2009} & Jung & $\begin{array}{l}\text { Explorar os recursos sociais como centralidade, hub e medidas autoritárias. } \\
\text { Detectar padrões de circulação em redes sociais. }\end{array}$ \\
\hline & Monclar et al. & $\begin{array}{l}\text { Fornecer o tamanho e a quantidade de atenção necessária em diferentes pontos } \\
\text { do tempo para verificar como o usuário administra a sua atenção. }\end{array}$ \\
\hline & Richards & $\begin{array}{l}\text { Validar o modelo em outros domínios problemáticos e estender as ideias para } \\
\text { colaboração em engenharia. }\end{array}$ \\
\hline & Wi et al. & Não apresenta. \\
\hline 2010 & Gao et al. & $\begin{array}{l}\text { Utilizar a ferramenta para avaliar o desempenho de um aplicativo sobre as } \\
\text { dimensões específicas da sociabilidade e estabelecer um perfil de sociabilidade. }\end{array}$ \\
\hline
\end{tabular}




\begin{tabular}{|c|c|c|}
\hline & Kaplan e Haenlein & Não apresenta. \\
\hline & $\begin{array}{l}\text { Kakali e } \\
\text { Papatheodorou }\end{array}$ & $\begin{array}{l}\text { Análise login em arquivos em combinação com estudos de usuários para melhorar } \\
\text { a tomada de decisão na exploração de padrões de informação. }\end{array}$ \\
\hline \multirow[t]{6}{*}{2011} & Chai et al. & $\begin{array}{l}\text { Considerar a intensidade da competitividade e a demanda incerta, como a } \\
\text { centralidade da rede afeta a vantagem competitiva nas redes formais e informais, } \\
\text { seu papel na promoção da aprendizagem interorganizacional e estudos } \\
\text { longitudinais. }\end{array}$ \\
\hline & Haefliger et al. & Desenvolver abordagens experimentais nas organizacões. \\
\hline & Hanna et al. & Não apresenta. \\
\hline & $\begin{array}{l}\text { Janhonen e } \\
\text { Johanson }\end{array}$ & $\begin{array}{l}\text { Aplicar a pesquisa em outros contextos e buscar dados objetivos para comparar } \\
\text { com dados subjetivos. }\end{array}$ \\
\hline & Kim et al. & Investigar os possíveis usos do modelo para pesquisa social. \\
\hline & Takaffoli et al. & Identificar padrões de uso nas redes sociais dinâmicas. \\
\hline \multirow[t]{3}{*}{2012} & Chai e Kim & $\begin{array}{l}\text { Expandir a amostra para diferentes idades e origens, investigar o impacto dos } \\
\text { sistemas de redes sociais como ferramenta de gestão e utilizar mais de um método } \\
\text { para validar os resultados. }\end{array}$ \\
\hline & Christidis et al. & $\begin{array}{l}\text { Usar métodos alternativos de modelagem probabilística para buscar insights em } \\
\text { qualidades adicionais dos tópicos de documentos. }\end{array}$ \\
\hline & Von Krogh & $\begin{array}{l}\text { Attention to management processes and mediation of co-evolution of social } \\
\text { software and organizations. }\end{array}$ \\
\hline 2013 & Chen & Expandir o escopo de aplicação do estudo. \\
\hline 2014 & $\begin{array}{l}\text { Pirkkalainen e } \\
\text { Pawlowsky }\end{array}$ & Estudos exploratórios e confirmatórios para relatar dependência de contexto. \\
\hline \multirow[t]{6}{*}{2015} & Antonius et al. & Melhorar as taxas de adesão ao software. \\
\hline & Atrash et al. & Adicionar conceitos como custo, qualidade e habilidades. \\
\hline & $\begin{array}{l}\text { Behringer e } \\
\text { Sassenberg }\end{array}$ & Testar os resultados em outras organizações e indústrias. \\
\hline & Pan et al. & $\begin{array}{l}\text { Investigar a qualidade da partilha de conhecimentos, verificar os mecanismos } \\
\text { psicológicos envolvidos e estudar efeitos amplos através das redes sociais. }\end{array}$ \\
\hline & Sigala e Chalkiti & $\begin{array}{l}\text { Compreender a dinâmica da interação homem-computador, sua influência nos } \\
\text { processos cognitivos e criativos e testar a pesquisa em outros contextos. }\end{array}$ \\
\hline & Zhang et al. & Não apresenta. \\
\hline \multirow[t]{6}{*}{2016} & Argote e Fahrenkopf & $\begin{array}{l}\text { Expansão do estudo da transferência de conhecimentos para novas áreas como o } \\
\text { empreendedorismo. }\end{array}$ \\
\hline & Kwahk e Park & $\begin{array}{l}\text { Incluir análise de indicadores objetivos de desempenho individual sobre o uso de } \\
\text { redes sociais, como densidade e centralização. }\end{array}$ \\
\hline & Lam et al. & $\begin{array}{l}\text { Mais pesquisas sobre os resultados operacionais das iniciativas corporativas em } \\
\text { MS, tanto no nível interno como na cadeia de suprimentos. }\end{array}$ \\
\hline & Limaj et al. & $\begin{array}{l}\text { Considerar outras medidas e métricas para as capacidades dos sistemas de } \\
\text { informação social. }\end{array}$ \\
\hline & $\begin{array}{l}\text { Mäntymäki e } \\
\text { Riemer }\end{array}$ & Identificar o impacto negativo do uso de redes sociais corporativas para a GC. \\
\hline & Mourtzis et al. & $\begin{array}{l}\text { Lidar com o número cada vez maior de dados e questões de proteção de business } \\
\text { intelligence. }\end{array}$ \\
\hline
\end{tabular}




\begin{tabular}{|c|c|c|}
\hline & Pillet e Carillo & $\begin{array}{l}\text { Explorar a natureza dos atributos de ferramentas colaborativas e atividades de } \\
\text { compartilhamento de conhecimento para explicar a variância adicional de } \\
\text { capacidade de compartilhamento de conhecimento. }\end{array}$ \\
\hline & Scott et al. & Incluir entrevistas para compreender a exploração e integração on-line fora da \\
\hline & Seo e Lee & $\begin{array}{l}\text { Ampliar os tipos de aplicações Web } 2.0 \text { e refletir as mudanças na tendência devido } \\
\text { ao rápido desenvolvimento. }\end{array}$ \\
\hline & Villanueva et al. & $\begin{array}{l}\text { Fazer uma análise de sentimentos baseada no modelo semântico para a } \\
\text { representação do conhecimento em SM. }\end{array}$ \\
\hline \multirow{4}{*}{2017} & Kane & Não apresenta. \\
\hline & Leon et al. & $\begin{array}{l}\text { Identificar o uso prático do conhecimento em MS; identificar os determinantes da } \\
\text { interrupção de uso de MS; estudar a centralização dos conhecimentos adquiridos } \\
\text { na MS pelos líderes, empregadores e departamentos. }\end{array}$ \\
\hline & Shang et al. & $\begin{array}{l}\text { Estudar as relações entre os recursos de rede e as consequências psicológicas } \\
\text { ou comportamentais das comunicações mídias sociais. }\end{array}$ \\
\hline & Whener et al. & Avançar na pesquisa de redes sociais empresariais em direções específicas. \\
\hline
\end{tabular}

Fonte: Autores.

No Quadro 5, pode-se notar que apenas cinco estudos (WI et al., 2009; KAPLAN; HEINELEIN, 2010; HANNA et al., 2011; ZHANG et al., 2015; KANE, 2016) não sugeriram desenvolvimentos futuros para a sua pesquisa. No entanto, as recomendações feitas nos 39 estudos restantes são questões pontuais, confirmadas por Whener et al. (2017). Por exemplo, a validação do estudo em outras nacionalidades, organizações e indústrias (MATSUO et al., 2007, BEHRINGER, SASSENBERG, 2015); utilização de métodos alternativos, aumento da amostra, melhoria das taxas de adoção e investigação da qualidade dos fenômenos, melhoria da compreensão da dinâmica ou adição de conceitos (ATRASH e cols., 2009; CHRISTIDIS et al., 2012, CHAl; KIM, 2012; ANTONIUS et al., 2015; PAN et al., 2015; SIGALA; CHALKITI, 2015). O empreendedorismo é uma área sugerida para a expansão de estudos sobre transferência de conhecimento e pode ser vinculado às ferramentas SM (ARGOTE; FAHRENKOPF, 2015). Estas questões são consideradas fundamentais para a evolução do conhecimento no âmbito dos estudos em curso.

Chai et al. (2011) sugerem estudos longitudinais sobre competitividade, demanda, aprendizagem interorganizacional e vantagem competitiva. Um ponto a ser acrescentado entre as questões abordadas neste estudo e outras oportunidades identificadas é a influência nos ambientes interno e externo das corporações com GC apoiada em MS (KWAK; PARK, 2016; LAM et al., 2016). São indicados mais estudos sobre questões de proteção, uso prático, uso negativo ou consequências comportamentais devido ao rápido desenvolvimento das MS nas corporações (MANTYMAKY; RIEMER, 2016; MOUTZIS et al., 2016; LEE, 2016; LEON et al. 2017; SHANG et al., 2017).

Estudos nestas direções podem ampliar a visão estratégica, ou seja, o progresso na compreensão para apoio à decisão com base nos vínculos entre os agentes internos (empresários e funcionários) e externos (fornecedores, clientes, consumidores e mercado) com o uso das MS para obter vantagem competitiva corporativa. Mais estudos sobre a evolução das mudanças nas formas de interagir, necessidade de aplicativos simples e determinantes da desistência do uso de MS para fins corporativos também são indicados. Além disso, os fatores comportamentais e psicológicos sobre os usuários e as suas interações precisam ser mais estudados.

\section{CONSIDERAÇÕES FINAIS}

As empresas precisam entender o processo de globalização social apoiado pela tecnologia da informação e do seu impacto na Gestão do Conhecimento. O principal objetivo deste estudo é identificar como os temas de Gestão do Conhecimento (GC) e Mídias Sociais (MS) estão relacionados na literatura científica para incentivar futuras pesquisas. Inicialmente, foi apresentada uma visão teórica sobre GC e MS. O foco desta discussão foi o papel estratégico da GC suportada pelas ferramentas MS incorporadas na Web 2.0. 
0 método de mapeamento de conhecimento científico denominado Processo de Construtivista de Desenvolvimento do Conhecimento (ProKnow- $C$ ) foi a ferramenta metodológica utilizada para selecionar o portfólio bibliográfico e realizar as análises bibliométrica e sistêmica, segundo o tema do presente estudo. ProKnow- $C$ viabilizou a busca, a organização de informações confiáveis em bases de dados científicos, a análise e a identificação de oportunidades para encorajar futuras pesquisas.

Os critérios bibliométricos foram ano de publicação e revistas com maior número de publicações na base Science Direct. Para a análise sistêmica, os critérios foram os principais conceitos, metodologias, resultados e oportunidades de pesquisa.

GC parece ser um conceito preconcebido nos artigos revisados. O conhecimento é visto como uma fonte de vantagem competitiva nas corporações. Os termos mídia social e rede social estão amplamente interligados. A diversidade de definições para os conceitos de redes sociais, mídias sociais e software social revela uma oportunidade para novos estudos.

Existe uma lacuna no desenvolvimento de estudos teóricos, qualitativos e mistos em relação aos estudos empíricos quanto à natureza dos métodos de pesquisa atuais. Em relação ao tipo, há carência de análise de conteúdo, experimentos, estudos de caso e simulações.

Os principais resultados dos estudos analisados indicam a necessidade de estabelecer melhores relações entre usuários em projetos de compartilhamento de informações. No entanto, há uma carência de pesquisas para verificar as possibilidades de desenvolvimento de novas competências para o uso de redes sociais.

As oportunidades de pesquisa indicam pontos específicos para o desenvolvimento do contexto, aplicação de novas metodologias, tipos de dados, escopo, tempo, população e aprofundamento dos estudos. A identificação das razões para a descontinuidade do uso das MS para fins corporativos e a busca por ferramentas simples e úteis são alternativas pouco exploradas. A influência positiva e negativa de aspectos comportamentais e psicológicos sobre os usuários também precisa ser mais bem investigada. Para pesquisas futuras, sugerem-se novos estudos sobre a influência dos ambientes interno e externo das corporações que usam MS para apoiar a GC como fonte de vantagem competitiva.

\section{REFERÊNCIAS}

ALCARÁ, A. et al. As redes sociais como instrumento estratégico para a inteligência competitiva. Transinformação, v.18, n.2, p.143-153, 2006.

ANTONIUS, N.; XU, J.; GAO, X. Factors influencing the adoption of Enterprise Social Software in Australia. Knowledge-Based Systems, v. 73, p. 32-43, 2015.

ARGOTE, L.; FAHRENKOPF, E. Knowledge transfer in organizations: The roles of members, tasks, tools, and networks. Organizational Behavior and Human Decision Processes, v. 136, p. 146-159, 2016.

ATRASH, A., et al. Note-taking as a main feature in a social networking platform for small and medium sized enterprises. Computers in Human Behavior, v. 51, p.705-714, 2015.

BEBENSEE, T.; HELMS, R.; SPRUIT, M. Exploring Web 2.0 applications as a means of bolstering up Knowledge Management. Electronic Journal of Knowledge Management, v. 9, p. 1-9, 2011.

BEHRINGER, N; SASSENBERG, K. Introducing Social Media for Knowledge Management: Determinants of employees' intentions to adopt new tools. Computers in Human Behavior, v. 48, p. 290-296, 2015.

BERNUS, P.; KALPIC, B. Business process modeling through the Knowledge Management perspective. Journal of Knowledge Management, v.10, n. 3, p. 40-56, 2006.

BROOKES, N. J., et al. Social processes, patterns and practices and project Knowledge Management: A theoretical framework and an empirical investigation. International Journal of Project Management, v. 24, n. 6, p.474-482, 2006.

BUKOWITZ, W. R.; WILLIAMS, R. L. Manual de Gestão do Conhecimento: Ferramentas e técnicas que criam valor 
para a empresa. Porto Alegre: Bookman, 2002.

CASTELLS, M. A Sociedade em Rede - a era da informação: Economia, Sociedade e Cultura. São Paulo: Atlas, 1999.

CHAl, K-H.; YAP, C-M; WANG, X. Network closure's impact on firms' competitive advantage: The mediating roles of knowledge processes. Journal of Engineering and Technology Management, v. 28, n.1-2, p. 2-22, 2011.

CHAI, S.; KIM, M. A socio-technical approach to knowledge contribution behavior: An empirical investigation of social networking sites users. International Journal of Information Management, v. 32, n.2, p.118-126, 2012.

CHEN, R. Member use of social networking sites-an empirical examination. Decision Support Systems, v. 54, n. 3, p. 1219-1227, 2013.

CHOW, W. S.; CHAN, L. S. Social network, social trust and shared goals in organizational knowledge sharing. Information \& Management, v.45, p. 458-465, 2008.

CHRISTIDIS, K.; MENTZAS, G.; APOSTOLOU, D. Using latent topics to enhance search and recommendation in Enterprise Social Software. Expert Systems with Applications, v. 39, n.10, p. 9297-9307, 2012.

ENSSLIN, L.; ENSSLIN, S. R.; LACERDA, R. T. O.; TASCA, J. E. ProKnow-C, Knowledge Development ProcessConstructivist. Processo técnico com patente de registro pendente junto ao INPI. Brasil, 2010.

GAO, Q.; DAI, Y.; FAN, Z.; KANG, R. Understanding factors affecting perceived sociability of social software. Computers in Human Behavior, v. 26, n.6, p.1846-1861, 2010.

HAEFLIGER, S.; MONTEIRO, E.; FORAY, D.; VON KROGH, G. Social Software and Strategy. Long Range Planning, v. 44, n. (5-6), p. 297-316, 2011.

HANNA, R.; ROHM, A.; CRITTENDEN, V. L. We're all connected: The power of the Social Media ecosystem. Business Horizons, v. 54, n. 3, p. 265-273, 2011.

JANHONEN, M.; JOHANSON, J-E. Role of knowledge conversion and social networks in team performance. International Journal of Information Management, v. 31, n.3, p. 217-225, 2011.

JUNG, J. J. Trustworthy knowledge diffusion model based on risk discovery on peer-to-peer networks. Expert Systems with Applications, v. 36, n.3, Part 2, p.7123-7128, 2009.

KAKALI, C.; PAPATHEODOROU, C. Exploitation of folksonomies in subject analysis. Library \& Information Science Research, v. 32, n.3, p. 192-202, 2010.

KANE, G.C., The evolutionary implications of Social Media for organizational Knowledge Management. Information and Organization, 2017. In press.

KAPLAN, A. M.; HAENLEIN, M. Users of the world, unite! The challenges and opportunities of Social Media. Business Horizons, v. 53, n.1, p. 59-68, 2010.

$\mathrm{KIM}$, H-N. et al. Collaborative user modeling with user-generated tags for social recommender systems. Expert Systems with Applications, v. 38, n.7, p. 8488-8496, 2011.

KWAHK, K.-Y.; PARK, D-H.The effects of network sharing on knowledge-sharing activities and job performance in enterprise Social Media environments. Computers in Human Behavior, 55, Part B, p. 826-839, 2016.

LACERDA, M. R. T.; ENSSLIN, L.; ENSSLIN, S. R. A Performance Measurement Framework in Portfolio Management: A Constructivist Case. Management Decision, v.49, n.4, p. 648-668, 2011.

LAM, H.K.S.; YEUNG, A.C.L; CHENG, T. C. E. The impact of firms' Social Media initiatives on operational efficiency and innovativeness. Journal of Operations Management, v.47, p. 28-43, 2016.

LEON, R.D., et al., Social network analysis: A tool for evaluating and predicting future knowledge flows from an insurance organization. Technological Forecasting and Social Change, v.114, p. 103-118, 2017.

LIMAJ, E., BERNROIDER, E.W.N.; CHOUDRIE, J. The impact of social information system governance, utilization, 
and capabilities on absorptive capacity and innovation: A case of Austrian SMEs. Information \& Management, v.53, n.3, p. 380-397, 2016.

MÄNTYMÄKI, M.; RIEMER, K. Enterprise social networking: A Knowledge Management perspective. International Journal of Information Management, v.36, n.6, Part A, p. 1042-1052, 2016.

MATSUO, Y. et al. POLYPHONET: An advanced social network extraction system from the Web. Journal of Web Semantics, v. 5, n.4, p.262-278, 2007.

MONCLAR, R. et al. MEK: Using spatial-temporal information to improve social networks and knowledge dissemination. Information Sciences, v. 179, n. 15, p. 2524-2537, 2009.

MOURTZIS, D.; DOUKAS, M.; MILAS, N. A knowledge-based social networking app for collaborative problem-solving in manufacturing. Manufacturing Letters, v. 10, p. 1-5, 2016.

NONAKA, l.; TAKEUCHI, H. Criação de conhecimento na empresa: como as empresas japonesas geram a dinâmica da inovação. Rio de Janeiro: Campus, 1997.

NONAKA, I.; VON KROGH, G. Perspective-tacit knowledge and knowledge conversion: controversy and advancement in organizational knowledge creation theory. Organization science, v. 20, n. 3, p. 635-652, 2009.

O'REILLY,T., 2005.WhatisWeb2.0?'Disponivelemhttp://www.oreillynet.com/pub/a/ oreilly/tim/news/2005/09/30/whatis-web-20.html. Acesso em dezembro de 2012.

PAN, S. L.; SCARBROUGH, H. Knowledge Management in practice: An exploratory case study. Technology Analysis \& Strategic Management, v. 11, n. 3, p. 359-374, 1999.

PAN, Y. et al. Integrating social networking support for dyadic knowledge exchange: A study in a virtual community of practice. Information \& Management, v.52, n.1, p. 61-70, 2015.

PILLET, J.-C.; CARILLO, K.D.A. Email-free collaboration: An exploratory study on the formation of new work habits among knowledge workers. International Journal of Information Management, v. 36, n.1, p. 113-125, 2016.

PIRKKALAINEN, H.; PAWLOWSKI, J. M. Global social Knowledge Management-understanding barriers for global workers utilizing social software. Computers in Human Behavior, v. 30, p. 637-647, 2014.

PORTER, M. E; MILLAR, V. E. How information gives your competitive advantage. Harvard Business Review, v. 63, n. 4, p.149-159, 1985.

RECUERO, R. Redes Sociais na Internet. Meridional: Porto Alegre, 2009.

RICHARDS, D. A social software/Web 2.0 approach to collaborative knowledge engineering. Information Sciences, v. 179, n. 15, p. $2515-2523,2009$.

SCOTT, K.S., K.H. SOROKTI; MERRELL, J. D. Learning "beyond the classroom" within an enterprise social network system. The Internet and Higher Education, v. 29, p. 75-90, 2016.

SEO, D.; LEE, J. Web_2.0 and five years since: How the combination of technological and organizational initiatives influences an organization's long-term Web_2.0 performance. Telematics and Informatics, v.33, n.1, p. 232-246, 2016.

SHANG, S.S.C; Y.-L, W.; LI, E. Y. Field effects of Social Media platforms on information-sharing continuance: Do reach and richness matter? Information \& Management, v.54, n.2, p. 241-255, 2017.

SIGALA, M.; CHALKITI, K. Knowledge Management, Social Media and employee creativity. International Journal of Hospitality Management, v. 45, p. 44-58, 2015.

TAKAFFOLI, M.; SANGI, F.; ZAIANE, O. R. Community Evolution Mining in Dynamic Social Networks. Procedia Social and Behavioral Sciences, v.22, n. 0, p.49-58, 2011.

TASCA, J. E.; ENSSLIN, L.; ENSSLIN, S. R.; ALVES, M. B. M. An approach for selecting a theoretical framework for the evaluation of training programs. Journal of European Industrial Training, v.34, n.7, p.631-655, 2010. 
TOMAÉL, M. I.; ALCARÁ, A. R.; DI CHIARA, I. G. Das redes sociais à inovação. Ciência da informação, v.34, n.2, p.93-104, 2005.

VAN BAALEN, P; BLOEMHOF-RUWAARD, J.; VAN HECK, E. Knowledge Sharing in an Emerging Network of Practice: The role of a knowledge portal. European Management Journal, v. 23, n.3, p. 300-314, 2005.

VILLANUEVA, D., et al. SMORE: Towards a semantic modeling for knowledge representation on Social Media. Science of Computer Programming, v121: p. 16-33, 2016.

VON KROGH, G. How does social software change Knowledge Management? Toward a strategic research agenda. The Journal of Strategic Information Systems, v.21, n.2, p.154-164, 2012.

WEHNER, B.: RITTER, C.; LEIST, S. Enterprise social networks: A literature review and research agenda. Computer Networks, v. 114, p. 125-142, 2017.

WI, H. et al. A team formation model based on knowledge and collaboration. Expert Systems with Applications, v.36, n.5, p. 9121-9134, 2009.

ZHANG X., et al. From e-learning to social-learning: Mapping development of studies on Social Media-supported Knowledge Management. Computers in Human Behavior, 51, Part B: p. 803-811, 2015. 